\title{
Building and Use of Infrastructure for Detector Development and Testing at VR-1 Reactor Facility
}

\author{
Tomas Bily \\ Dept. of Nuclear Reactors, FNSPE \\ Czech Technical University in Prague \\ Prague, Czech Republic \\ tomas.bily@fjfi.cvut.cz
}

\author{
Jan Rataj \\ Dept. of Nuclear Reactors, FNSPE \\ Czech Technical University in Prague \\ Prague, Czech Republic \\ jan.rataj@fjfi.cvut.cz
}

\author{
Ondrej Huml \\ Dept. of Nuclear Reactors, FNSPE \\ Czech Technical University in Prague \\ Prague, Czech Republic \\ ondrej.huml@fjfi.cvut.cz
}

\begin{abstract}
Activities related to detector development, testing, characterisation and applications belong to key research objectives of the VR-1 reactor facility. The contribution gives a review of related improvements, achievements, used approaches, methods, and trends.
\end{abstract}

Keywords-VR-1 reactor, neutron detection, detector development

\section{INTRODUCTION}

Neutron and gamma detection and spectrometric systems have plenty of research and industrial applications. Development of such systems and adaptation of their use for specific application often requires extensive experimental effort. At VR-1 reactor facility operated by the Czech Technical University in Prague the infrastructure for detector development and testing is being developed to provide experimental support in all phases of detection system development. This includes conditions for initial detector testing, detection system characterisation and calibration, and application oriented testing.

\section{VR-1 REACTOR FACILITY}

The VR-1 reactor facility is primarily oriented on education and training with significant international impact in this field $[1,2]$. The utilization for research activities covers typically about $20-30 \%$ of operational time. The research utilisation has been widening since 2012 when the facility was included among the large research infrastructures supported by the Ministry of Education, Youth and Sports of the Czech Republic. Since then the open access to the facility for the purposes of research, development and innovation has been enabled which made the utilization of the facility by external users significantly easier and more effective.

The reactor itself is of open-pool light-water type with zero power and low enriched uranium fuel. It has a simple access to the core through a set of dry vertical channels with diameters ranging from $16 \mathrm{~mm}$ to $90 \mathrm{~mm}$ and one horizontal radial channel with diameter up of $250 \mathrm{~mm}$ which can be reduced to $90 \mathrm{~mm}$. The reactor can operate in a wide range of neutron fluxes (up to some $10^{9} \mathrm{n} / \mathrm{cm}^{2} \mathrm{~s}$ ) and may provide various ratios of neutron and gamma component. The facility further possesses several dedicated adjacent labs: gamma spectrometry lab, radiation interaction lab, neutron lab and electronics lab. Gamma spectrometry lab is used mainly for neutron activation analysis of samples irradiated in the reactor. Radiation interaction lab is used mainly for education on basics of radiation detection. It can also be used for initial detection testing covering detector response to alpha, beta or gamma radiation. Weak calibration sources are mostly shared with gamma spectrometry lab. Medium activity Cs-137 source (0.8 GBq) is available to study gamma sensitivity of neutron detectors. Neutron lab is dedicated for utilisation of radionuclide neutron sources of $\mathrm{Am}-\mathrm{Be}$ and $\mathrm{Cf}-252$ type and future plans incorporates the set-up with DD generator as well.

\section{DEVELOPMENT OF INFRASTRUCTURE TO SUPPORT DETECTOR DEVELOPMENT AND TESTING}

The infrastructure is gradually being improved utilizing a strong synergy between own research, education \& training activities, and activities of open access users. The own research is to a high degree aimed on development of research capabilities of the facility through broader offer of neutron source types, dedicated characterized radiation fields for specific tests, and development of methods related to radiation measurements and signal processing. With respect to neutron sources, the facility originally utilized beside the VR-1 reactor two radionuclide neutron sources of Am-Be type. The weaker one with neutron emission rate of ca. $2 \times 10^{5} \mathrm{n} / \mathrm{s}$ serves mainly to study response of detection systems to neutron radiation; the stronger one with emission rate of ca $1 \times 10^{7} \mathrm{n} / \mathrm{s}$ was used for advanced tests and experiments in neutron lab. In 2013, a portable DD generator with maximal neutron emission rate of $7 \times 10^{6} \mathrm{n} / \mathrm{s}$ has been acquired; it is aimed to be used coupled with the VR-1 as well as an independent facility. Beside different neutron energy spectra it enables to provide pulsing ranging from $250 \mathrm{~Hz}$ to $20 \mathrm{kHz}$ with adjustable pulse width. Its neutron output can be modified based on high voltage and beam current set-up. Due to its portable and compact design it may be used in various set-up and geometries. In 2014, the $0.8 \mathrm{MBq}$ Cs-137 source was bought to enable studies of gamma sensitivity of neutron detection systems and to enlarge the abilities in education training with gamma radiation detectors. In 2018, the new neutron lab was developed and a Cf-252 neutron source was acquired. The source enables experiments in fission neutron spectrum. Simultaneously, the storage container for neutron radionuclide sources was built in the lab. Later dedicated irradiation positions have been developed inside storage container to enable long term irradiation in close geometry with achievable dose rate of ca. $8 \mathrm{mGy} / \mathrm{h}$. The irradiation can be performed in tailored capsules that can be attached to the front-end of the shielding plug of the source storage container. To further improve the flexibility of available neutron sources and neutron radiation fields, a portable DT generator is being acquired. Again, a portable, flexible device with a choice of continuous or pulsing operation is envisaged. Thereafter, the facility would be able to cover various needs of testing in all common neutron energy 
spectra at a single site. This can be advantageously used in development of both neutron detection and spectrometric systems.

Together with variety of sources the variety of neutron radiation fields and their characterisation belongs to factor improving the facility capability. For neutron field characterisation techniques based on foil activation [3] and Monte Carlo calculations are standardly being used. Recently, in frame of open-access to the facility, a testing of on-line neutron spectrometric system has been performed which helped to further characterize the radiation field in radial channel of the reactor $[4,5]$.

Further, next to reactor shielding the polyethylene cube with several vertical channels have been developed. The central channel can be connected with the reactor fast post systems. This enables for studies in radiation field coming from irradiated samples (typically delayed neutrons, or gamma radiation from uranium samples). However, the cube design enables to insert other neutron source inside the central channel and detectors or samples into the remaining to perform specific tests. Specific set-ups and experiments in various geometries and environments, incl. polyethylene, water, or graphite are prepared in the neutron lab. They can serve for optimization of neutron detector performance, and its basic characterisation (e.g. sensitivity or angular dependence). In the field of complex gamma radiation fields, the capability of the facility has been significantly improved during 2013-2015 when the MONTE project was realized together with National Radiation Protection Institute. In frame of the project special set-up has been developed to study detector response in complex gamma field of irradiated nuclear fuel $[6,7,8]$. This supports testing and experiments in gamma detection and spectrometric system research and applications.

The strengthening and development of own research of the facility is further supported to improve the capabilities and attractiveness of the facility for open access users. One of the three key activities is studies related to behaviour of detection systems in a nuclear reactor core and external neutron sources environments. Standardly, besides testing at various steady-state power levels, the reactor enables to perform various transients that can be advantageously used for detector testing. The reactor is further equipped with several experimental devices capable to change the core conditions: e.g. device for dynamic experiments (oscillator), device for bubble-boiling simulation, and instrumentation for temperature-reactivity effects studies. Using these devices research for neutron detector applications covering in-core diagnostics or noise techniques is enabled. Further development is being performed with shut-down (subcritical) reactor with multiple external neutron sources in the core. This can simulate conditions similar to those in power reactor during core reconfigurations where the selffissioning of used fuel may challenge detector applications e.g. in reactivity-meters.

\section{USERS}

The backbone of users utilizing the infrastructure for detector development, testing (incl. application oriented testing) has been formed within the university and covers activities related to neutron detector development, improvements of methods for neutron detector characterisation (e.g. non-linearity characterisation, pulse processing, etc.), neutron detector testing and characterisation (e.g. in the frame of competence centre for advanced detection system of ionizing radiation). The facility is used by other local research institutions such as Research Centre Rez [4, 5] or National Radiation Protection Institute, by local companies producing and developing neutron detectors and as well by detection systems users such as radiation units of Czech Fire \& Rescue Service. From the international users that have recently utilized the infrastructure for detectors related research, Defense Academy of the UK, or CEA France [9] can be mentioned.

\section{CONCLUSIONS}

At VR-1 reactor facility, the infrastructure for detector development and testing is being gradually developed utilizing synergies between own research, external user research and education and training. The facility tends to provide support in all steps of development, from initial functional tests, through device characterisation up-to application oriented testing at one site.

\section{ACKNOWLEDGMENT}

The paper was supported by the project "Strengthening and development of research at Czech Technical University in Prague with the use of research infrastructure VR-1 Training Reactor for research activities" (reg. nr. CZ.02.1.010.00.016_0130001790) supported by Operational Programme Research, Development and Education cofinanced from European Structural and Investment Funds and from state budget of the Czech Republic.

\section{REFERENCES:}

[1] L. Sklenka, M. Kropík, "Training courses at VR-1 reactor". Proceedings of the International Conference Nuclear Energy for New Europe 2006

[2] L. Sklenka, J. Rataj, "Education and Training in the Field of Reactor Physics and Technology through Research Reactor Networks \& Coalitions". Transaction of the American Nuclear Society, Vol. 107, San Diego, California 2012. La Grande Park, Illinois: American Nuclear Society, 2012. pp. 1243-1246. ISSN 0003-018X.

[3] M. Štefánik, K. Katovský, M. Vinš, L Závorka, J. Šoltés, "Neutron field for activation experiments in horizontal channel of training reactor VR-1". Radiation Physics and Chemistry. 2014, 104 302-305. ISSN 0969-806X.

[4] M. Košt’ál, E. Losa, Z. Matěj, V. Juříček, D. Harutyunyan, O. Huml, M. Štefánik, F. Cvachovec et al., "Characterization of mixed N/G beam of the VR-1 reactor". Annals of Nuclear Energy. 2018, 122 6978. ISSN 0306-4549.

[5] Z. Matěj, M. Košt'ál, E. Losa, O. Huml, M. Štefánik, F. Cvachovec, F. Mravec, V. Přenosil "Measurement of fast neutron spectra in radial channel of VR-1 research reactor" Radiation Physics and Chemistry. 2019, ISSN 0969-806X.

[6] O. Huml, P. Žlebčík, L. Sklenka, J. Rataj, M. Štefánik, "Monte Carlo Simulation of Radionuclide Inventory of Irradiated Nuclear Fuel for Generation of Complex Fission Gamma Ray Fields". 2015 IEEE Nuclear Science Symposium \& Medical Imaging Conference, San Diego, 31 October - 7 November 2015 
[7] P. Žlebčík, H. Malá, P. Rulík, O. Huml, L. Sklenka, "MONTE-1 experimental device for detection system testing in fission radionuclide fields" (Experimentální zařízení MONTE-1 pro testování detekčních systémů $\mathrm{v}$ polích štěpných produktů) BJE. 2016, 24(62)(1/2), 28-32. ISSN 1210-7085.

[8] P. Žlebčík, O. Huml, H. Malá, P. Rulík, M. Hýža, J. Škrkal, B. Bulánek, J. Hůlka, et al., "Comparison of various detection systems in real fission field". In: FOURTH EUROPEAN IRPA CONGRESS, Geneve, Book of Abstracts, 2014. pp. 249. ISBN 978-2-8399-1520-5

[9] M. Pomorski, Ch. Mer-Calfati, F.Foulon L'. Sklenka, J. Rataj, T. Bily, "Diamond as a solid state micro-fission chamber for thermal neutron detection at the VR-1 research reactor". Conference: ANIMMA 2015: 4. International Conference on Advancements in Nuclear Instrumentation Measurement Methods and their Applications, Lisboa (Portugal), 20-24 Apr 2015. 